\title{
Cardiovascular Imaging in Patients with Chronic Kidney Disease
}

\author{
Cristina Karohla ${ }^{\mathrm{a} b}$ Paolo Raggi ${ }^{\mathrm{a}}$ \\ a Division of Cardiology and Department of Medicine, Emory University School of Medicine, Atlanta, Ga., USA;

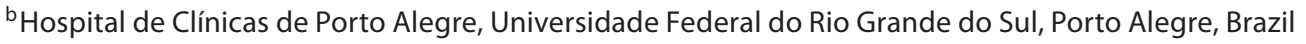

\section{Key Words}

Cardiovascular imaging $\cdot$ Cardiovascular disease $\cdot$

Calcification - Chronic kidney disease

\begin{abstract}
Cardiovascular disease is highly prevalent in chronic kidney disease and has been associated with increased morbidity and mortality. Several morphological and functional tests are available to assess the cardiovascular system. Since structural and functional cardiovascular abnormalities have prognostic implications, their identification may become crucial for the implementation of effective preventive and therapeutic strategies. We review the most frequently used imaging methods to investigate structural and functional cardiovascular changes in patients with chronic kidney disease.
\end{abstract}

Copyright $\odot 2011$ S. Karger AG, Basel

\section{Introduction}

In the recent past, the interest in cardiovascular disease complications in patients with chronic kidney disease (CKD) has greatly intensified. In fact, the cardiovascular morbidity and mortality of these patients is a magnitude greater than that of the general population [1]. Besides traditional factors, CKD patients are exposed to unique risk factors, such as altered mineral metabolism, enhanced oxidative stress and inflammation, volume and pressure overload. Several CKD patients develop a form of uremic cardiomyopathy that results both in systolic and diastolic ventricular dysfunction. Valvular calcification and vascular calcification (VC), known to be extensive in CKD and believed to be secondary to a combination of accelerated atherosclerosis and altered mineral metabolism, likely contribute to the development of uremic cardiomyopathy. In this disease state, extensive intramyocardial fibrosis may predispose to reentry arrhythmias and sudden death [2].

As the presence of cardiovascular abnormalities has prognostic and therapeutic implications, their identification may become crucial for the implementation of effective preventive and therapeutic strategies. In this review, we will discuss the utilization of imaging methods to investigate structural as well as functional changes of the cardiovascular system in patients with CKD.

\section{Structural Imaging Tests}

Several methods are available to investigate structural cardiovascular changes: planar X-rays, computed tomography (CT), cardiac magnetic resonance (CMR), echocardiography, and ultrasound (US).

\section{KARGER}

Fax +41613061234

E-Mail karger@karger.ch

www.karger.com
() 2011 S. Karger AG, Basel

0253-5068/11/0313-0130\$38.00/0

Accessible online at:

www.karger.com/bpu
Paolo Raggi, MD

Emory University School of Medicine

1365 Clifton Rd NE, AT-504

Atlanta, GA 30322 (USA)

Tel. +1 404778 5414, Fax +1 404778 3540,E-Mail praggi@emory.edu 


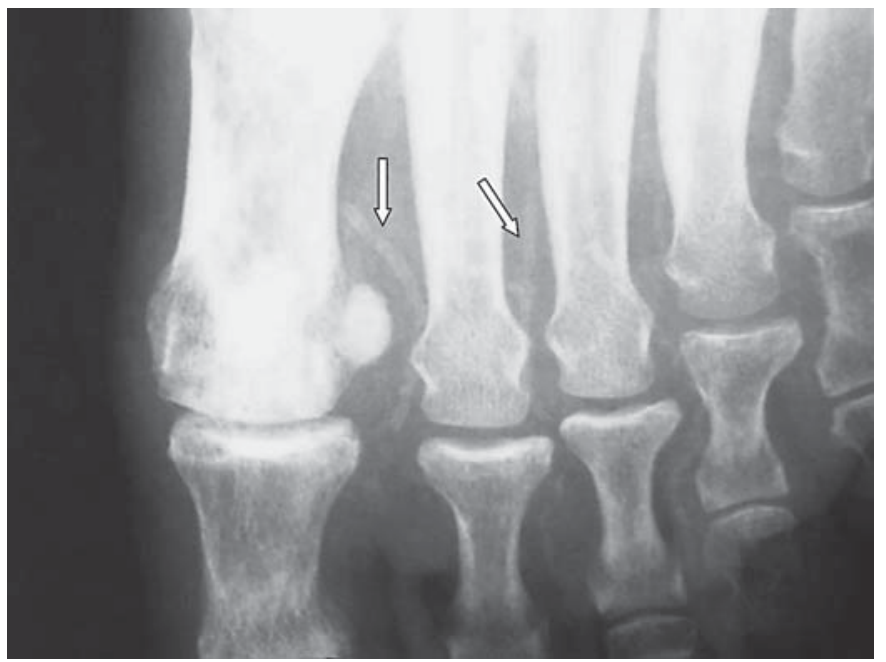

Fig. 1. Plane X-ray of a 40-year-old diabetic patient undergoing hemodialysis treatment for 6 years showing calcification of the intermetatarsal arteries of the right foot.

\section{Planar X-Ray}

Single-plane (planar) radiography is a simple, widely available and inexpensive tool that can be used to evaluate the presence of VC (fig. 1). Although mostly qualitative, several semiquantitative methods have been developed. The best known is the one originally proposed by Kaupila et al. [3] whereby calcification of the abdominal aorta (AAC), visualized on a lateral X-ray of the lumbar spine, is given a score of $0-24$ based on the number and extent of calcified foci in the aortic segments extending in front of lumbar vertebrae 1-4. Other methods include the simple VC score (SVCS) proposed by Adragão et al. [4], and plane X-rays of the pelvis and thigh for ileofemoral calcification [5].

The SVCS was used in an observational study of 123 hemodialysis patients followed for a mean of 37 months. The presence of calcification in the femoral, iliac, radial, and digital arteries was scored from 0 (no visible calcification) to 8 (all vessels calcified). Some degree of VC was detected in $75 \%$ of the study patients, and more than half of them had a score $\geq 3$. During 37 months of follow-up, the SCVS was associated with higher risk of cardiovascular events, hospitalization and death (hazard risk, HR, for score $\geq 3$ : $3.9 ; 95 \%$ CI 1.1-13.4; $\mathrm{p}=0.03$ ) [4].

The AAC score was initially described for quantification of VC in a subgroup of 617 Framingham Heart Study participants. The AAC score was shown to be predictive of cardiovascular events and mortality in two cohorts of the Framingham Heart Study [6, 7]. In an observational study of 515 maintenance hemodialysis patients, Okuno et al. [8] showed that the AAC score was predictive of allcause mortality (HR 2.07; 95\% CI 1.21-3.56; $\mathrm{p}<0.05$ ) and cardiovascular mortality (HR 2.39; 95\% CI 1.01-5.66; p < $0.05)$ after adjustment for age, hemodialysis duration, diabetes mellitus, serum albumin level, and C-reactive protein level.

No study has yet evaluated the use of the SVCS and the AAC score in patients with early CKD. The qualitative nature of planar radiography limits its applicability to sequential imaging. The ongoing multicenter study CORD (Calcification Outcome in Renal Disease), a European observational study of dialysis patients, might answer some of these questions in the near future [9].

\section{Computed Tomography}

Electron beam CT (EBCT) and multislice CT (MSCT) are well validated as the reference standard for assessing coronary artery calcification (CAC). Although these CTbased techniques operate on the basis of different imaging platforms, they are considered equivalent in accuracy and reproducibility [10]. EBCT employs a rotating fan of Xrays produced by the impact of a beam of electrons against a tungsten ring; the image acquisition is very rapid and occurs only once per heart beat, toward end diastole; this limits greatly the radiation exposure to the patient. MSCT employs a paired X-ray source detector unit revolving around the patient who lies on a radiological cradle advancing through the revolving beam of X-rays; this newer technology provides a higher radiation dose than EBCT. With MSCT it is possible to obtain 2-320 simultaneous sections according to the brand and model of CT used [11]. With both CT techniques, it is possible to accurately detect and quantify the extent of calcification of the coronary arteries, the aorta and the cardiac valves. Quantification is performed with a score such as the Agatston [12], the volume [13], and the mass method [14]. Although the volume and mass scores are slightly more reproducible and more appropriate for use with modern MSCTs, the Agatston score is the most frequently used and reported method. The Agatston score is calculated as the product of a calcified plaque area by a coefficient related to the peak CT density measured within the same plaque. The sum of all scores of all calcified lesions identified along the coronary tree constitutes the total coronary artery calcium score (CACS). CT imaging cannot clearly differentiate the location of calcium in the intimal or medial layer of the vessel wall. Furthermore, there is only a weak association between CACS and the severity of obstructive coronary artery disease (CAD) $[15,16]$ (fig. 2). 
Braun et al. [17] were the first to utilize EBCT to quantify the extent of CAC in CKD 5D patients. They reported that CACS was much higher in hemodialysis patients compared to healthy individuals as well as patients with known CAD. Similar observations were reported by Goodman et al. [18] in pediatric and young dialysis patients. More recently, investigators showed that progressive decline of renal function is associated with increased prevalence of CAC [19]. The prevalence of CAC in CKD $5 \mathrm{D}$ was reported to be as high as $80-85 \%$, while in CKD stages $3-5$, CAC is detected in approximately $40-60 \%$ of the subjects [20-25]. These findings suggest that CAC tends to progress and increases dramatically after initiation of dialysis.

The presence and severity of CAC has been demonstrated to be a strong predictor of cardiovascular events and death in the general population, while the literature regarding CKD patients is still limited. Matsuoka et al. [21] reported a lower survival in $104 \mathrm{CKD}$ stage 5D patients with CACS greater than the median compared to CACS below the median $(\mathrm{p}=0.01)$. Block et al. [26], in a cohort of 129 incident hemodialysis patients followed prospectively for 44 months, reported that the presence of a baseline CACS $>400$ was a strong predictor of mortality (HR 4.5, 95\% CI 1.33-15.14) after adjustment for age, race, gender and diabetes. In two retrospective analyses, Russo et al. [27] and Shantouf et al. [28] reported a higher risk of all-cause mortality with increasing CACS.

In addition to assessing outcome, several trials have employed serial CT to evaluate the impact of medical interventions on CAC. Four studies compared the impact of two phosphate-binding agents, sevelamer and calcium-based binders, and a very recent one compared the effect of sensipar and vitamin D [20, 29-32]. Most studies showed a difference between interventions, suggesting that CAC may be a valid surrogate marker for research.

There are several limitations to CT-based imaging such as the high equipment cost, the impractical and improbable use for in-office imaging, the required expertise to perform the test and interpret the results, and finally the radiation exposure to the patient. In view of these limitations, other methods to assess and measure VC have been investigated and sometimes compared to CT imaging [27, 33-35]. Though CT angiography has seen a rapid development in recent years, both for the assessment of coronary anatomy and left ventricular function, its application to CKD patients is very limited at the time of this writing, and no recommendation can be given.

\section{Ultrasonography}

US-based imaging techniques have been used extensively to evaluate vascular disease in CKD patients. Ultrasonography is very helpful in assessing superficial vessels such as the femoral and carotid arteries. Like planar $\mathrm{X}$-ray, US techniques provide only a qualitative assessment of VC. However, high-resolution US transducers can be used to identify carotid plaques and measure the intima-media thickness of the carotid wall (C-IMT).

C-IMT, a surrogate marker of preclinical atherosclerosis, measures the thickness of both the tunica intima and media of the carotid arteries. C-IMT is increased in the presence of several cardiovascular risk factors such as age, hypertension, hyperlipidemia, diabetes mellitus, inflammation and smoking [36]. CKD has also been reported to be a risk factor for increased C-IMT. Kawamoto et al. [37] evaluated 428 men and 582 women, and reported a significant inverse association between estimated glomerular filtration rate (eGFR) and C-IMT independent of other common cardiovascular risk factors. Several studies also reported an increased C-IMT both in adults and pediatric CKD patients undergoing dialysis as well as renal transplant patients compared with healthy controls [38-40].

The association of C-IMT with an increased risk of events has been clearly established in the general population, but not as well in CKD yet. Benedetto et al. [41] performed sequential carotid echo-Doppler studies in 135 dialysis patients (90 on hemodialysis and 45 on peritoneal dialysis) for a mean follow-up of 15 months. Although the number of plaques increased at a rate of 1 plaque/patient/year and the proportion of patients with severe atherosclerosis ( $>4$ plaques) increased from $25 \%$ at baseline to $44 \%$ at follow-up ( $<<0.001)$, C-IMT did not change. Moreover, an increase in C-IMT was not predictive of the development of new atherosclerotic plaques and cardiovascular outcome, whereas an increase in number of carotid plaques was a strong predictor of cardiovascular events [HR 1.22 (95\% CI 1.05-1.42; p = 0.01) for 1 plaque/year increase].

Unlike dialysis patients, the link between carotid intima-media thickness and cardiovascular disease in CKD stage 3-5 remains to be clarified. In an observational study of 203 Chinese patients (mean age $53.8 \pm 10.9$ years) in CKD stage 3-4, C-IMT was associated with cardiovascular events [HR, 40.2\% (95\% CI 2.9-91\%; $p=0.03$ ) for each higher quartile of C-IMT], but not with mortality after an average follow-up of 52.4 months [42]. On the other hand, Zoungas et al. [43] reported that C-IMT was not a significant predictor of cardiovascular events after 
adjustment for other cardiovascular risk factors in a cohort of 315 patients in CKD stage 4-5.

In some studies, C-IMT has been positively associated [44], and in others it was not associated [38] with CAC; similarly, an association has been found with flow-mediated vasodilatation in some [45] but not in other studies $[40,46]$. Finally, a weak association between pulse wave velocity $(\mathrm{PWV})$ and C-IMT has also been described $(\mathrm{R}=$ $0.27 ; \mathrm{p}=0.005)$ [47].

These results suggest that C-IMT may be associated not only with structural but also with functional abnormalities of the vessel wall and endothelium.

\section{Echocardiography}

For a long time, echocardiography was the gold standard for assessment of ventricular structure and function as well as valvular function. With the advent of cardiac MR and cardiac CT, some of these functions have been claimed by the more modern techniques. However, the distinct advantages of transthoracic echocardiography, with a compendium of M-mode, two-dimensional (2-D echo) and more recently three-dimensional imaging (3-D echo), are the noninvasive nature of the test, the wide availability of the tool, the moderate cost of the equipment and the ability to assess structural and functional parameters during the same test.

The most frequently evaluated parameters are chamber size, such as left atrial diameter and volume, left ventricular size and mass (LVM), and left ventricular systolic and diastolic function. A known pitfall of echocardiography in CKD is the overestimation of LVM due to volume retention during the interdialytic period. With real-time 3-D echo, accuracy and reproducibility of chamber volume and mass have improved and became comparable to CMR [48]. An enlarged left atrial volume, a surrogate marker of diastolic dysfunction, has been associated with cardiovascular events and mortality [49].

Stress echocardiography has been employed with good results in risk stratification of CAD in CKD. Sensitivity $(88 \%)$ and specificity $(94 \%)$ of stress echocardiography for the diagnosis of obstructive CAD is high in $\mathrm{CKD}$ patients [50]; furthermore, a positive dobutamine stress echo is highly predictive of major cardiovascular events [51].

Valvular calcification can be assessed only qualitatively, although the mere presence of calcification of one or two valves has been associated with a poor outcome in dialysis patients [52]. Obviously, the hemodynamic significance of valvular disease can be accurately assessed with echocardiography that remains the gold standard for this purpose.

Cardiovascular Imaging in Chronic Kidney Disease

\section{CMR Imaging}

Cardiovascular magnetic resonance allows an accurate assessment of the structure and function of several cardiovascular structures, and has become an extremely useful clinical and research tool in the general population. However, CMR imaging has seen little utilization in CKD so far.

CMR is the current gold standard to evaluate left ventricular mass, volume and ejection fraction without the need for contrast administration, and is more accurate than 2-D echo [53]. Recently, Moran et al. [54] reported an inverse association between LVH by CMR and cystatin-based eGFR in a sample of 4,971 participants in the Multi-Ethnic Study of Atherosclerosis. As CMR is an accurate volume-independent measurement of cardiac mass in CKD patients, it is emerging as the premiere research tool for evaluating impact of interventions [5557].

CMR is of great utility in identifying myocardial fibrosis and prior myocardial infarction [58] with delayed gadolinium hyperenhancement. However, gadolinium should be avoided in patients with advanced renal dysfunction (eGFR $<30 \mathrm{ml} / \mathrm{min} / 1.75 \mathrm{~m}^{2}$ ) due to the risk of nephrogenic systemic fibrosis [59].

Finally, CMR is apt to study aortic distensibility and stiffness. Aortic distensibility assessed by CMR was an independent predictor of cardiovascular events and death in 144 CKD stage 5 and $5 \mathrm{D}$ patients after 2 years of followup [60].

\section{Functional Methods}

\section{Myocardial Perfusion Imaging}

Myocardial perfusion imaging (MPI), either singlephoton emission CT or positron emission tomography, are the reference standards for the noninvasive assessment of coronary circulatory function (fig. 2). These methods are based on the use of radioactive tracers that are extracted by the myocardium from the circulation. They provide information on global and segmental myocardial perfusion at rest and after stress. The latter is achieved with exercise or pharmacologically with injection of vasodilators (dipyridamole, adenosine or regadenoson) or inodilators (inotropic-vasodilating drugs such as dobutamine). Positron emission tomography also allows the assessment of coronary flow reserve, an index of coronary vasodilator capacity, calculated as the ratio of maximum myocardial blood flow (MBF) during stress to $\mathrm{MBF}$ at rest. 

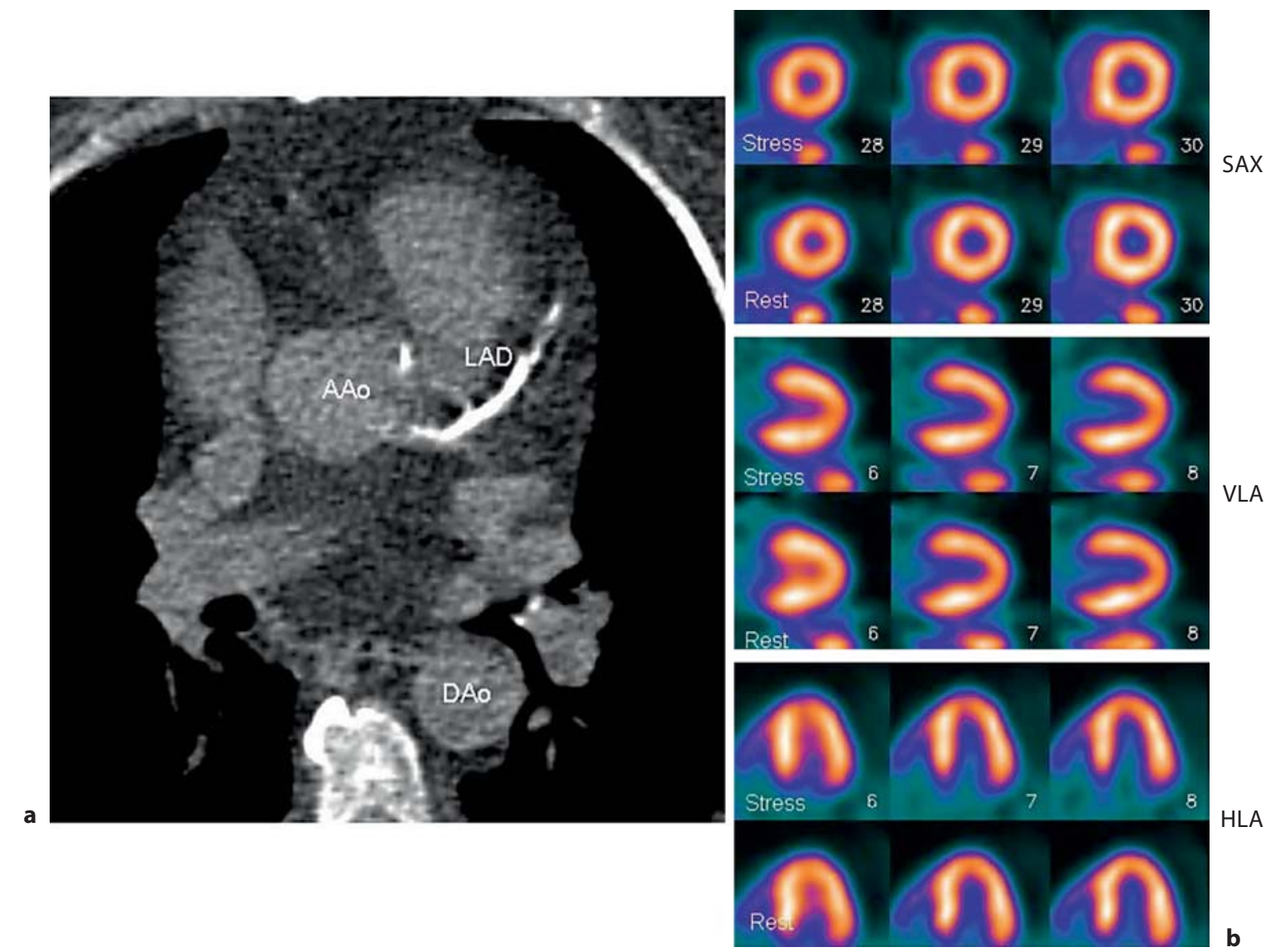

Fig. 2. Axial CT image of the chest (a) and corresponding myocardial perfusion image of the same hemodialysis patient before and after stress (b). The chest CT image shows extensive calcification (total calcium score $=$ 886) of the left anterior descending coronary artery (LAD), while the nuclear stress test shows normal myocardial perfusion at rest and after stress. AAo = Ascending aorta; DAo = descending aorta; HLA = horizontal longaxis images; SAX = short-axis images; VLA = vertical long-axis images.

Although MPI has traditionally been used to identify perfusion abnormalities due to coronary disease, it has become apparent that perfusion abnormalities may occur in the absence of critical stenoses. In this case, the abnormalities are considered secondary to coronary microcirculatory or endothelial dysfunction.

MPI is frequently performed for risk stratification prior to surgery in renal transplant candidates, although there is no consensus regarding the indication and frequency of performance of this test. Several studies have demonstrated that an abnormal MPI is associated with an unfavorable cardiovascular outcome across all stages of CKD, including incident and prevalent dialysis patients [61-63]. MPI should not be used to screen for CAD in patients with CKD, but is indicated for patients with clinical and electrocardiographic evidence of CAD and patients with advanced CKD stages who underwent an incomplete revascularization [64].

\section{Assessment of Arterial Elasticity - PWV}

The elastic properties of arteries change with age, advancing stages of diabetes mellitus, hypertension, and CKD $[65,66]$. The most notable change is an increase in arterial stiffness that can be measured with methods such as PWV. The test is based on measurement of the velocity of propagation of a pressure wave (forward pressure wave) generated by the ejection of blood from the left ventricle. The wave is reflected at arterial branching points generating reflected waves that travel back toward the left ventricle. The test is noninvasive and requires the detec- 
tion of a pressure wave at the carotid and the femoral level (i.e. aortic PWV) by means of a tonometer or Doppler probe, timed to the EKG. As arterial stiffness increases, so does the travel velocity of the forward and reflected waves (i.e. PWV increases). The faster return of the reflected waves imposes an increase in afterload (pressure work) on the left ventricle resulting in LVH and reduced coronary perfusion.

Arterial stiffness has been reported to worsen as eGFR declines [67], and there is an association between VC and increased aortic stiffness in CKD patients [22, $34,47,68]$. Importantly, PWV is a strong predictor of all-cause and cardiovascular mortality in CKD 5D patients $[68,69]$.

Although PWV has been extensively employed as a research tool, there is no current recommendation for its use in clinical practice. Of interest, preliminary studies have shown that arterial stiffness may be attenuated with medical interventions in CKD patients $[57,70]$. Therefore, PWV could become a useful clinical tool in the near future to evaluate the impact of therapeutic interventions in CKD patients.

\section{Conclusion}

Noninvasive methods for morphological and functional assessment of the cardiovascular system have the potential to improve the care of patients with CKD. Echocardiography is recommended for screening of all patients starting renal replacement therapy [64]. MPI is frequently used to evaluate renal transplant candidates for CAD. Simple tests, such as lateral abdominal radiography and echocardiography, are appropriate alternatives to CT methods to detect vascular and valvular calcification. Surprisingly, despite the fact that VC is highly prevalent and has prognostic implications, screening for it in CKD patients is not recommended [71]. It is the opinion of the authors that this position should be revised in view of the strong positive predictive value of the test as well as the powerful negative predictive value of the absence of cardiovascular calcification. Furthermore, CT remains a useful research tool to determine the effect of various interventions on the progression of VC.

\section{Disclosure Statement}

Paolo Raggi received research grants from Genzyme Therapeutics and Amgen.

\section{References}

1 Foley RN, Parfrey PS, Sarnak MJ: Epidemiology of cardiovascular disease in chronic renal disease. J Am Soc Nephrol 1998;9:S16S23.

-2 Glassock RJ, Pecoits-Filho R, Barberato SH: Left ventricular mass in chronic kidney disease and ESRD. Clin J Am Soc Nephrol 2009; 4:S79-S91.

-3 Kaupila LI, Polack JF, Cupples LA, Hannan MT, Kiel DP, Wilson PW: New indices to classify location, severity and progression of calcific lesions in the abdominal aorta: a 25year follow-up study. Atherosclerosis 1997; 132:245-250.

-4 Adragão T, Pires A, Lucas C, Birne R, Magalhaes L, Gonçalves M, Negrão AP: A simple vascular calcification score predicts cardiovascular risk in haemodialysis patients. Nephrol Dial Transplant 2004; 19:14801488.

5 London GM, Guérin AP, Marchais SJ, Métivier F, Pannier B, Adda H: Arterial media calcification in end-stage renal disease: Impact on all-cause and cardiovascular mortality. Nephrol Dial Transplant 2003;18:17311740 .
6 Wilson PWF, Kaupila LI, O‘Donnell CJ, Kiel DP, Hannan MT, Polack JF, Cupples LA: Abdominal aortic calcific deposits are an important predictor of vascular morbidity and mortality. Circulation 2001;103:1529-1534.

7 Walsh CR, Cupples LA, Levy D, Kiel DP, Hannan MT, Wilson PW, O'Donnell CJ: Abdominal aortic calcific deposits are associated with increased risk for congestive heart failure: The Framingham Heart Study. Am Heart J 2002;144:733-739.

8 Okuno S, Ishimura E, Kitatani K, Fujino Y, Kohno K, Maeno Y, Maekawa K, Yamakawa T, Imanishi Y, Inaba M, Nishizawa Y: Presence of abdominal aortic calcification is significantly associated with all-cause and cardiovascular mortality in maintenance hemodialysis patients. Am J Kidney Dis 2007; 49:417-425.

-9 Honkanen E, Kauppila L, Wikstrom B, Rensma PL, Krzesinski J, Aasarod K, Verbeke F, Jensen PB, Mattelaer P, Volck B: Abdominal aortic calcification in dialysis patients: results of the CORD study. Nephrol Dial Transplant 2008;23:4009-4015.
10 Stanford W, Thompson BH, Burns TL, Heery SD, Burr MC: Coronary artery calcium quantification at multi-detector row helical CT versus electron-beam CT. Radiology 2004;230:397-402.

11 Hurlock GS, Higashino H, Mochizuki T: History of cardiac computed tomography: Single to 320-detector row multislice computed tomography. Int J Cardiovasc Imaging 2009;25:31-42.

12 Agatston AS, Janowitz WR, Hildner FJ, Zusmer NR, Viamonte MJ, Detrano R: Quantification of coronary artery calcium using ultrafast computed tomography. J Am Coll Cardiol 1990;15:827-832.

13 Callister TQ, Cooil B, Raya SP, Lippolis NJ, Russo DJ, Raggi P: Coronary artery disease: improved reproducibility of calcium scoring with an electron-beam CT volumetric method. Radiology 1998;208:807-814.

14 Rumberger JA, Kaufman L: A rosetta stone for coronary calcium risk stratification: Agatston, volume, and mass scores in 11,490 individuals. AJR Am J Roentgenol 2003;181: 743-748. 
15 Rosen BD, Fernandes V, McClelland RL, Carr JJ, Detrano R, Bluemke DA, Lima JAC: Relationship between baseline coronary calcium score and demonstration of coronary artery stenoses during follow-up. JACC Cardiovasc Imaging 2009;2:1175-1183.

-16 Haydar AA, Hujairi NMA, Covic AA, Pereira D, Rubens M, Goldsmith DJA: Coronary artery calcification is related to coronary atherosclerosis in chronic renal disease patients: a study comparing EBCT-generated coronary artery calcium scores and coronary angiography. Nephrol Dial Transplant 2004; 19:2307-2312.

17 Braun J, Oldendorf M, Moshage W, Heidler R, Zeitler E, Luft FC: Electron beam computed tomography in the evaluation of cardiac calcification in chronic dialysis patients. Am J Kidney Dis 1996;27:394-401.

$\checkmark 18$ Goodman WG, Goldin J, Kuizon BD, Yoon C, Gales B, Sider D, Wang Y, Chung J, Emerick A, Greaser L, Elashoff RM, Saluski IB: Coronary-artery calcification in young adults with end-stage renal disease who are undergoing dialysis. N Engl J Med 2000;342: 1478-1483.

19 Kramer H, Toto R, Peshock R, Cooper R, Victor R: Association between chronic kidney disease and coronary artery calcification: The DALLAS Heart Study. J Am Soc Nephrol 2005; 16:507-513.

20 Chertow GM, Burke SK, Raggi P: Sevelamer attenuates the progression of coronary and aortic calcification in hemodialysis patients. Kidney Int 2002;62:245-252.

-21 Matsuoka M, Iseki K, Tamashiro M, Fujimoto N, Higa N, Touma T, Takishita S: Impact of high coronary artery calcification score (CACS) on survival in patients on chronic hemodialysis. Clin Exp Nephrol 2004;8:5458.

-22 Sigrist M, Bungay P, Taal MW, McIntyre CW: Vascular calcification and cardiovascular function in chronic kidney disease. Nephrol Dial Transplant 2006;21:707-714.

-23 Garland JS, Holden RM, Groome PA, Lam M, Nolan RL, Morton AR, Pickett W: Prevalence and association of coronary artery calcification in patients with stages 3 to $5 \mathrm{CKD}$ without cardiovascular disease. Am J Kidney Dis 2008;52:849-858.

- 24 Adeney KL, Siscovick DS, Ix JH, Seliger SL, Shlipak MG, Jenny NS, Kestenbaum BR: Association of serum phosphate with vascular and valvular calcification in moderate CKD. J Am Soc Nephrol 2009;20:381-387.

-25 Russo D, Palmiero G, De Blasio AP, Balletta MM, Andreucci VE: Coronary artery calcification in patients with CRF not undergoing dialysis. Am J Kidney Dis 2004;44:10241030.

26 Block GA, Raggi P, Bellasi A, Kooienga L, Spiegel DM: Mortality effect of coronary calcification and phosphate binder choice in incident hemodialysis patients. Kidney Int 2007;71:438-441.
27 Russo D, Morrone LF, Brancaccio S, Napolitano P, Salvatore E, Spadola R, Imbriaco M, Russo CV, Andreucci VE: Pulse pressure and presence of coronary artery calcification. Clin J Am Soc Nephrol 2009;4:316-322.

28 Shantouf RS, Budoff MJ, Ahmadi N, Ghaf fari A, Flores F, Gopal A, Noori N, Jing J, Kovesdy CP, Kalantar-Zadeh K: Total and individual coronary artery calcium scores as independent predictors of mortality in hemodialysis patients. Am J Nephrol 2010;31: 419-425.

29 Block GA, Spiegel DM, Ehrlich J, Mehta R, Lindbergh J, Dreisbach A, Raggi P: Effects of sevelamer and calcium on coronary artery calcification in patients new to hemodialysis. Kidney Int 2005;68:1815-1824.

-30 Barreto DV, Barreto FC, Carvalho AB, Cuppari L, Draibe SA, Dalboni MA, Moyses RM, Neves KR, Jorgetti V, Miname M, Santos RD, Canziani MEF: Phosphate binder impact on bone remodeling and coronary calcificationresults from the BRIC study. Nephron Clin Pract 2008:110:c273-c283.

-31 Qunibi W, Moustafa M, Muenz LR, He DY, Kessler PD, Diaz-Buxo JA, Budoff M: A 1-year randomized trial of calcium acetate versus sevelamer on progression of coronary artery calcification in hemodialysis patients with comparable lipid control: The Calcium Acetate Renagel Evaluation-2 (CARE-2) study. Am J Kidney Dis 2008;51:952-965.

32 Floege J, Raggi P, Block GA, Torres PU, Csiky B, Naso A, Nossuli K, Moustafa M, Goodman WG, Lopez N, Downey G, Dehmel B, Chertow GM: Study design and subject baseline characteristic in the ADVANCE study: effects of cinacalcet on vascular calcification in haemodialysis patients. Nephrol Dial Transplant 2010;25:1916-1923.

- 33 Bellasi A, Ferramosca E, Muntner P, Ratti C, Wildman RP, Block GA, Raggi P: Correlation of simple imaging tests and coronary artery calcium measured by computed tomography in hemodialysis patients. Kidney Int 2006;70:1623-1628.

34 Raggi P, Bellasi A, Ferramosca E, Islam T, Muntner P, Block GA: Association of pulse wave velocity with vascular and valvular calcification in hemodialysis patients. Kidney Int 2007;71:802-807.

35 Stompór T, Rajzer M, Pasowicz M, Krasniak A, Sulowicz W, Kawecka-Jaszcz K, Tracz W, Janda K, Tabor B, Kowalczyk-Michalek ME, Wójcik K, Konieczynska M, Klimeczek P, Janusz-Grzybowska E: Coronary artery calcification, common carotid artery intima-media thickness and aortic pulse wave velocity in patients on peritoneal dialysis. Int J Artif Organs 2006;29:736-744.

- 36 Hurst RT, Ng DW, Kendall C, Khandheria B: Clinical use of carotid intima-media thickness: review of the literature. J Am Soc Echocardiogr 2007;20:907-914.
37 Kawamoto R, Ohtsuka N, Kusunoki T, Yorimitsu N: An association between the estimated glomerular filtration rate and carotid atherosclerosis. Intern Med 2008;47:391398.

38 Oh J, Wunsch R, Turzer M, Bahner M, Raggi P, Querfeld U, Mehls O, Schaefer F: Advanced coronary and carotid arteriopathy in young adults with childhood-onset chronic renal failure. Circulation 2002;106:100-105.

-39 Delucchi A, Dinamarca H, Gainza H, Whitttle C, Torrealba I, Iñiguez G: Carotid intimamedia thickness as a cardiovascular risk marker in pediatric end-stage renal disease patients on dialysis and in renal transplantation. Transplant Proc 2008;40:3244-3246.

-40 Kocak H, Gumuslu S, Sahin E, Ceken K, Ermis C, Gocmen AY, Yakupoglu G, Ersoy FF, Suleymanlar G, Tuncer M: Relationship between carotid artery intima-media thickness and brachial artery flow-mediated dilatation in peritoneal dialysis patients. Int Urol Nephrol 2009;41:409-416.

41 Benedetto FA, Tripepi G, Mallamaci F, Zoccali C: Rate of atherosclerotic plaque formation predicts cardiovascular events in ESRD. J Am Soc Nephrol 2008;19:757-763.

42 Szeto CC, Chow KM, Woo KS, Chook P, Kwan BC, Leung CB, Li PK: Carotid intima media thickness predicts cardiovascular diseases in Chinese predialysis patients with chronic kidney disease. J Am Soc Nephrol 2007; 18:1966-1972.

-43 Zoungas S, Cameron JD, Kerr PG, Wolfe R, Muske C, McNeil JJ, McGrath BP: Association of carotid intima-medial thickness and indices of arterial stiffness with cardiovascular disease outcomes in CKD. Am J Kidney Dis 2007;50:622-630.

44 Kurnatowska I, Grzelak P, Stefanczyk L, Nowicki M: Tight relations between coronary calcification and atherosclerotic lesions in the carotid artery in chronic dialysis patients. Nephrology (Carlton) 2010;15:184189.

-45 Enderle MD, Schroeder S, Ossen R, Meisner C, Baumbach A, Haering HU, Karsch KR, Pfohl M: Comparison of peripheral endothelial dysfunction and intimal media thickness in patients with suspected coronary artery disease. Heart 1998;80:349-354.

-46 Yan RT, Anderson TJ, Charbonneau F, Title L, Verma S, Lonn E: Relationship between carotid artery intima-media thickness and brachial artery flow-mediated dilation in middle-aged healthy men. J Am Coll Cardiol 2005;45:1980-1986.

$\checkmark 47$ Lemos MM, Jancikic AD, Sanches FM, Christofalo DM, Ajzen SA, Miname MH, Santos RD, Fachini FC, Carvalho AB, Draibe SA, Canziani MEF: Pulse wave velocity - a useful tool for cardiovascular surveillance in pre-dialysis patients. Nephrol Dial Transplant 2007;22:3527-3532. 
-48 Nikitin NP, Constantin C, Loh PH, Ghosh J, Lukaschuk EI, Bennett A, Hurren S, Alamgir F, Clark AL, Cleland JG: New generation 3-dimensional echocardiography for left ventricular volumetric and functional measurements: comparison with cardiac magnetic resonance. Eur J Echocardiogr 2006;7: 365-372.

-49 Tripepi G, Benedetto FA, Mallamaci F, Tripepi R, Malatino L, Zoccali C: Left atrial volume in end-stage renal disease: a prospective cohort study. J Hypertens 2006;24:11731180 .

50 Sharma R, Pellerin D, Gaze DC, Gregson H, Streather CP, Collinson PO, Brecker SJD: Dobutamine stress echocardiography and the resting but not exercise electrocardiograph predict severe coronary artery disease in renal transplant candidates. Nephrol Dial Transplant 2005;20:2207-2214.

51 Tita C, Karthikeyan V, Stroe A, Jacobsen G, Ananthasubramaniam K: Stress echocardiography for risk stratification in patients with end-stage renal disease undergoing renal transplantation. J Am Soc Nephrol 2008; 21:321-326.

52 Wang AY, Wang M, Woo J, Lam CW, Li PK, Lui SF, Sanderson JE: Cardiac valve calcification as an important predictor for all-cause mortality and cardiovascular mortality in long-term peritoneal dialysis patients: a prospective study. J Am Soc Nephrol 2003;14: 159-168.

-53 Stewart GA, Foster JE, Cowan M, Rooney E, McDonagh T, Dargie HJ, Rodger RS, Jardine AG: Echocardiography overestimates left ventricular mass in hemodialysis patients relative to magnetic resonance imaging. Kidney Int 1999;56:2248-2253.

54 Moran A, Katz R, Jenny NS, Astor B, Bluemke DA, Lima JAC, Siscovick DS, Bertoni AG, Shlipak MG: Left ventricular hypertrophy in mild and moderate chronic kidney disease determined using cardiac magnetic resonance imaging and cystatin C: The MultiEthnic Study of Atherosclerosis. Am J Kidney Dis 2008;52:839-848.
55 Patel RK, Oliver S, Mark PB, Powell JR, McQuarrie EP, Traynor JP, Dargie HJ, Jardine AG: Determinants of left ventricular mass and hypertrophy in hemodialysis patients assessed by cardiac magnetic resonance imaging. Clin J Am Soc Nephrol 2009;4:14771483.

56 McGill RL, Biederman RWW, Getts RT, Hazlett SM, Sharma SB, Duran J, Brandys DE, Sysak JC, Sureshkumar KK, Sandroni SE, Marcus RJ: Cardiac magnetic resonance imaging in hemodialysis patients. J Nephrol 2009;22:367-372.

57 Edwards NC, Steeds RP, Stewart PM, Ferro CJ, Townend JN: Effect of spironolactone on left ventricular mass and aortic stiffness in early-stage chronic kidney disease: a randomized controlled trial. J Am Coll Cardiol 2009;54:505-512.

58 Andrade JM, Gowdak LHW, Giorgi MCP, Paula FJ, Kalil-Filho R, Lima JJG, Rochitte CE: Cardiac MRI for detection of unrecognized myocardial infarction in patients with end-stage renal disease: comparison with ECG and scintigraphy. AJR 2009;193:W25W32.

59 Hasebroock KM, Serkova NJ: Toxicity of MRI and CT contrast agents. Expert Opin Drug Metab Toxicol 2009;5:403-416

60 Mark PB, Doyle A, Blyth KG, Patel RK, Weir RAP, Steedman T, Foster JE, Dargie HJ, Jardine AG: Vascular function assessed with cardiovascular magnetic resonance predicts survival in patients with advanced chronic kidney disease. J Cardiovasc Magn Reson 2008; 10:39.

61 Hase H, Joki N, Ishikawa H, Saijyo T, Tanaka Y, Takahashi Y, Inishi Y, Imamura Y, Nakamura M, Moroi M: Independent risk factors for progression of coronary atherosclerosis in hemodialysis patients. Ther Apher Dial 2006; 10:321-327.

62 Momose M, Babazono T, Kondo C, Kobayashi H, Nakajima T, Kusakabe K: Prognostic significance of stress myocardial ECG-gated perfusion imaging in asymptomatic patients with diabetic chronic kidney disease on initiation of haemodialysis. Eur J Nucl Med Mol Imaging 2009;36:1315-1321.
63 Hatta T, Nishimura S, Nishimura T: Prognostic risk stratification of myocardial ischaemia evaluated by gated myocardial perfusion SPECT in patients with chronic kidney disease. Eur J Nucl Med Mol Imaging 2009; 36:1835-1841.

64 K/DOQI clinical practice guidelines for cardiovascular disease in dialysis patients. Am J Kidney Dis 2005;45:S1-S153.

65 Townsend RR, Wimmer NJ, Chirinos JA, Parsa A, Weir M, Perumal K, Lash JP, Chen J, Steigerwalt SP, Flack J, Go AS, Rafey M, Rahman M, Sheridan A, Gadegbeku CA, Robinson NA, Joffe M: Aortic PWV in chronic kidney disease: a CRIC ancillary study. Am J Hypertens 2010;23:282-289.

-66 Sengstock D, Sands RL, Gillespie BW, Zhang X, Kiser M, Eisele G, Vaitkevicius P, Kuhlmann M, Levin NW, Hinderliter A, Rajagopalan S, Saran R: Dominance of traditional cardiovascular risk factors over renal function in predicting arterial stiffness in subjects with chronic kidney disease. Nephrol Dial Transplant 2010;25:853-861.

67 Wang MC, Tsai WC, Chen JY, Huang JJ: Stepwise increase in arterial stiffness corresponding with the stages of chronic kidney disease. Am J Kidney Dis 2005;45:494-501.

-68 Adragão T, Pires A, Birne R, Curto JD, Lucas C, Gonçalves M, Negrão AP: A plain X-ray vascular calcification score is associated with arterial stiffness and mortality in dialysis patients. Nephrol Dial Transplant 2009; 24:997-1002.

69 Blacher J, Guerin AP, Pannier B, Marchais SJ, Safar ME, London GM: Impact of aortic stiffness on survival in end-stage renal disease. Circulation 1999;99:2434-2439.

70 Guérin AP, Blacher J, Pannier B, Marchais SJ, Safar ME: Impact of aortic stiffness attenuation on survival of patients in end-stage renal failure. Circulation 2001;103:987-992.

71 KDIGO clinical practice guideline for the diagnosis, evaluation, prevention, and treatment of chronic kidney disease - mineral and bone disorder (CKD-MBD). Kidney Int 2009;113:S1-S130. 